\title{
Implementing STEM technology in a Title One middle school classroom
}

\section{Carolyn Holcomb}

Carolyn Holcomb, "Implementing STEM technology in a Title One middle school classroom," Proc. SPIE 8729, Scanning Microscopies 2013: Advanced Microscopy Technologies for Defense, Homeland Security, Forensic, Life, Environmental, and Industrial Sciences, 87290E (29 May 2013); doi: $10.1117 / 12.2016152$

Event: SPIE Defense, Security, and Sensing, 2013, Baltimore, Maryland, United States 


\title{
Implementing STEM Technology in a Title One Middle School Classroom
}

\author{
Carolyn Holcomb
}

Western Heights Middle School

\begin{abstract}
What do a modern day CSI forensics lab and an electron microscope have in common? It offers the ability to engage students in a scientific investigation, exploring the world of nanotechnology using modern day equipment. $7^{\text {th }}$ grade students at Western Heights Middle School at Hagerstown, MD, used Hitachi's TM3000 to better understand how technology is utilized when investigating contemporary questions. Using the TM3000, students learned how to load samples, scan, take pictures, and focus the SEM. This experience was an eye opener to students who otherwise would never have had such a learning opportunity. As a result many verbalized interest in pursuing careers in STEM related fields, if only to be able to use such fun equipment. In this session the teacher will present how the instrument was used, and the lessons learned both by the instructor and her students.
\end{abstract}

\subsection{INTRODUCTION}

It often happens in academic settings that technology is reserved for the gifted and talented classrooms as an extension for motivated and accelerated learners. STEM funds and technological equipment are often earmarked for special programs and charter schools. Similarly, engaging labs are available to those enrolled in specialized extracurricular STEM opportunities often found in weekend enrichment classes and summer camps. In both cases, this targeted population of students is already on a college and career readiness track.

Western Heights Middle School is a Title One school serving an inner city population with an enrollment of 550. Its students' math and reading scores are well below state and national levels. In 2012, these students received scores on the $8^{\text {th }}$ grade Science Maryland School Assessments, ranking them lowest in the county. Not just focusing on our high achieving learners, all of our seventh graders were targeted to participate in a hands-on STEM project through Hitachi's educational outreach program. With the use of their TM3000 Tabletop Microscope, our objective was to supplement and expand the school's microscopy unit. In this activity, students were presented with basic background knowledge of microscopy and then tasked with analyzing faux forensic data to stop a local terrorist threat.

\subsection{Engaging the Unengaged Learner}

Teaching the importance of STEM technology can be challenging. Capturing the minds and interests of $7^{\text {th }}$ graders in an impoverished community is a greater challenge still. It is not the material assets which underserved students lack which makes teaching a challenge, but the lack of general background knowledge. Taking advantage of current popular shows such as NCIS and CSI, a scenario was created in which the students became investigators, tasked with solving a case using state of the art technology. In order to make the students' learning experience more meaningful and successful, it was first necessary to introduce basic ideas of relative size as well as introduce optical 
equipment used to see things on a micro versus macro level. Students were given visual comparisons between images as seen through a light microscope with those of a SEM. Additionally, students were provided with basic working knowledge of how images were created by optical instruments, and the inherent limitations of both methods. Once the foundation of information was laid, students were then given the learning challenge. Students were given a manufactured scenario of a bioterrorist attack in which they were forensic scientists who had to positively identify and match the antidote to a neurotoxin, by comparing three plant samples. What was the tool of choice for this investigation? Hitachi's TM3000!

\subsection{Learning Increases When Students Take Ownership of Their Work}

On its own, the TM3000 Tabletop Microscope drew little interest. Until it was identified as an important forensics tool, it was believed to be a new classroom computer. These students were quite awed to learn that such an expensive piece of technology could be so small and unassuming. To further pique students' interests, the "investigative area," housing the TM3000, was roped off by police caution/crime scene tape. A taped outline of a fallen body was evidenced on the floor.

Prior to entering the area, the students were divided into two learning groups of 10-15. It was necessary to maintain small learning groups to ensure that all students had a personal and specific role in the hands-on activity.
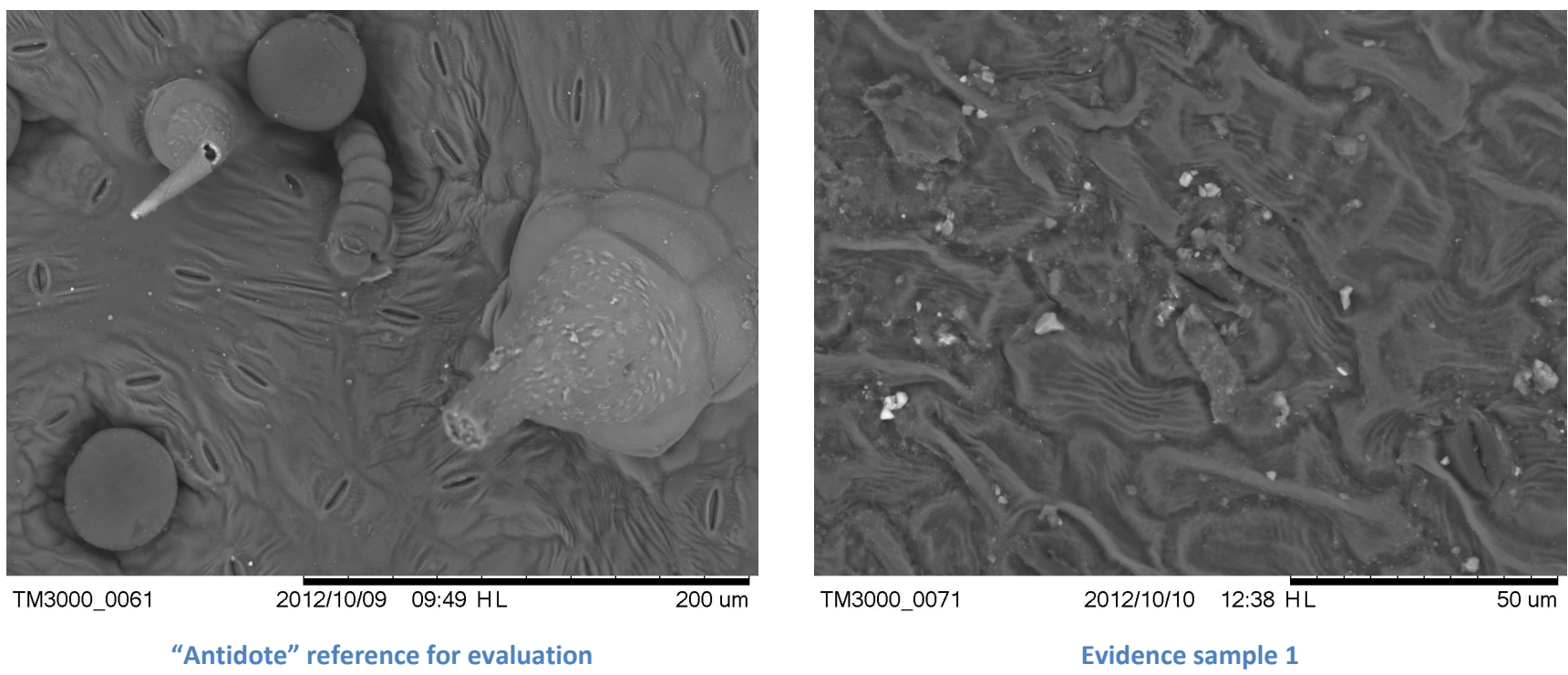

One group used computers to electronically investigate a virtual electron microscope, examining samples and generating written responses regarding interesting facts discovered. Meanwhile, the "crime scene" group remained with the lead teacher. Each of these students had been previously assigned a specific role in the investigation. These jobs varied from Evidence Holder to Sample Loader, SEM vacuum Facilitator, EM photographer, and Focus Technician. Each role was explained as the teacher modeled proper use of the microscope. Each student had a worksheet identifying their assignment, as well as space to draw images they viewed on the computer monitor. 
Students were provided with three pre-generated plant samples, ready to be loaded into the microscope. Sample leaves were taken from local schoolyard plants: a sunflower, a clover and a maple leaf. Additionally, students were given a SEM image of the yet un-identified "antidote" taken from the bioterrorist. Three other SEM labeled images were to later aid in the correct identification of the various plant samples. The main objective was to correctly match up one of the samples with terrorist's antidote.

At this point in the lab, the teacher assumed the role of facilitator as each student took ownership of this investigation and more importantly, of their own learning. Each quickly became an expert, not only of their role, but of their teammates. This learning exercise was an excellent opportunity to develop collaborative skills, and to explore the importance of teamwork essential within the STEM community. The two separated groups switched, and the exercises were repeated until each section had made successful identifications.

\section{Eliminating Downtime is the Key to Success}

When working with the SEM, it is important to factor in that there are inherent moments of waiting, as samples are loaded and unloaded. Waiting for the vacuum pump to expel air to view samples, and later waiting for the sample chamber to refill with air, can feel more like hours than minutes to eager students and anxious teachers. Every seasoned instructor knows that such "downtime" can be the downfall of any carefully planned lab or lesson. To prevent breakdown and chaos, it was necessary to prepare for these periods with related activities to maintain student engagement. These moments became opportunities for students to explore how samples were prepared. This was also an excellent time for students to explore other SEM images provided by Hitachi, making predictions of how macroscopic items changed in appearance when viewed microscopically. Connections to botany, and the exchange of gases, were also made as students were able to view stomata apparent on the plant images.

\section{Conclusions and Reflections}

Many important lessons were learned beyond how to use an electron microscope. It was shown that when given the right environment and opportunity, almost all students become excited about science. Historically, such opportunities are only given to those already motivated in this field. However, this lesson demonstrated that academic success can be found when all students, regardless of prior interest or background, are provided access to engaging technology. Students who previously voiced frustration and a dislike of science due to what they viewed as "unreachable" concepts, suddenly found success, which quickly bloomed into self confidence. This exercise afforded them the opportunity to examine the very real possibility that, yes, they could successfully enter STEM careers. Furthermore, it allowed the teacher the platform to praise, encourage and to plant the idea, that they saw in each student the potential to become a needed participant in the STEM community.

Every planned classroom lesson has room for improvement, and this activity was no exception. Many teachers are fearful of engaging in "extra" activities since they are obligated to complete curriculum guidelines within a specific time frame. This instructor faced the same dilemma. As a result, these two exercises, the virtual and hands-on lab, were conducted in one 80 minute block. While it ensured that all 200 students were exposed to the instrument within a two day period, not throwing the precious learning schedule off by too much, the activity often felt rushed to both instructor and students. Ideally, if interdisciplinary grade level teams could collaboratively plan this activity, this lab could be run over many days, integrating multiple content areas, while 
meeting mandated objectives. Extended time would have permitted students to explore different roles when operating the instrument, and to explore the SEM in greater detail.

This instructor and members of her school are grateful to the Hitachi cooperation, and to its team, for making this technology available to a population who rarely benefits from such opportunities.

Proc. of SPIE Vol. 8729 87290E-4

Downloaded From: https://www.spiedigitallibrary.org/conference-proceedings-of-spie on 26 Apr 2023 Terms of Use: https://www.spiedigitallibrary.org/terms-of-use 